\title{
Behind the scenes: Unravelling the molecular mechanisms of p53 target gene selectivity (Review)
}

\author{
LEONIE SMEENK $^{1}$ and MARION LOHRUM ${ }^{1,2}$ \\ ${ }^{1}$ Department of Molecular Biology, Faculty of Science, Nijmegen Centre for Molecular Life Sciences, \\ Radboud University Nijmegen, Nijmegen, The Netherlands; ${ }^{2}$ Georg-Speyer-Haus, \\ Paul-Ehrlich-Strasse 42-44, Frankfurt, Germany
}

Received July 27, 2010; Accepted August 20, 2010

DOI: 10.3892/ijo_00000757

\begin{abstract}
The p53 protein is a tumor suppressor that plays a crucial role in cellular growth regulation inducing a plethora of response pathways. p53 post-translational modifications, p53-binding proteins, co-factors and the p53-family members p63 and p73 have all been described to contribute to p53 target gene regulation and hence cellular outcome. However, the molecular mechanisms that discriminate between the different p53-responses towards stress treatments have remained largely elusive. This review focuses on the topic of the molecular mechanisms behind target gene selectivity of the transcription factor p53 and provides insight into the latest era of p53 research.
\end{abstract}

\section{Contents}

1. Introduction

2. Regulation of activity

3. p53 target gene selection

4. Future outlook

\section{Introduction}

The p53 protein was first discovered 30 years ago and was found to associate with simian virus 40 Large $\mathrm{T}$ protein (SV40LT) while accumulating in the nuclei of cancer cells (1-3). The gene encoding p53 (TP53) was cloned from neoplastic rodent and human cells. Several groups showed at the same time that this form of p53 had oncogenic activity when introduced together with the ras gene in transformation assays (4-6). However, in the late 1980s it turned out that the DNA plasmids used for these original experiments were

Correspondence to: Dr Marion Lohrum, Georg-Speyer-Haus, Paul-Ehrlich-Strasse 42-44, D-60596 Frankfurt, Germany

E-mail: lohrum@em.uni-frankfurt.de

Key words: p53, target gene selection, stress-response mutant p53 clones; the wild-type p53 did not transform cells, but rather inhibited oncogene mediated transformation (7-9). Soon, it was discovered that p53 was frequently mutated in a variety of human cancers $(10,11)$ and germ-line p53 mutations were found in patients with Li-Fraumeni syndrome, a rare autosomal dominant hereditary disorder which leads to the occurrence of several types of cancer $(12,13)$. Mice deficient for $\mathrm{p} 53$ were shown to be susceptible to spontaneous tumors (14).

One of the first identified functions of the tumor suppressor p53 was its ability to bind to DNA and to function as a transcription factor (15-20). About the same time it was discovered that p53 can control apoptosis (21) and cell cycle arrest (22). In the meanwhile it has become evident that p53 can also act independently from transcriptional regulation to induce apoptosis (23).

In unstressed cells, p53 is maintained at low levels due to a very short protein half-life and it becomes rapidly stabilized upon cellular and genomic stress. A key component in regulating p53 levels is the p53-interacting protein mouse double minute 2 (MDM2) (24-26). MDM2 (HDM2 in humans) is itself a p53 transcriptional target $(27,28)$, and was shown to inhibit the p53 transcriptional activity as well as to decrease p53 protein levels, establishing a negative feedback loop (29). Further studies showed that MDM2 is an E3 ubiquitin ligase and induces ubiquitin mediated proteasomal degradation of p53 thereby regulating p53 stability $(30,31)$. Whereas polyubiquitination is important for the p53 protein degradation, monoubiquitination of $\mathrm{p} 53$ by MDM2 results in nuclear export of p53 (32). Homozygous deletion of MDM2 is lethal in mice due to p53-mediated apoptosis during early embryogenesis, while deletion of both MDM2 and p53 gives rise to mice that develop normally, demonstrating the importance of MDM2 in regulating p53 activation $(33,34)$. Thus, MDM2 controls the ubiquitination, nuclear export and degradation of p53. Another important regulator of p53 is MDMX (MDM4), a p53-binding protein, homologous to MDM2, but with little E3 ligase activity itself $(35,36)$. MDMX can heterodimerize with MDM2 and this complex appears to be a better E3ubiquitin ligase than MDM2 alone (37). MDMX knockout mice are also lethal, and similar to MDM2, this lethality is rescued by inactivation of p53 $(38,39)$. Furthermore, MDM2 and MDMX play important and distinct roles in the regulation of the p53 transactivation activity (40). The activity of MDM2 
towards p53 can be regulated by several proteins that bind to MDM2. The p14Arf protein as well as the ribosomal proteins L5, L11, L23, S7, the nucleolar proteins nucleophosmin (NPM) and nucleostemin (NS) impinge on the MDM2mediated ubiquitination of p53 (41-47). Also other E3ubiquitin ligases have been reported to ubiquitinate p53, such as Pirh2, COP1 and ARF-BP1 (48-50), but their exact contribution to p53 degradation is unknown. The p53-stability is also regulated via de-ubiquitination, e.g. by the Herpesvirusassociated ubiquitin-specific protease (HAUSP) (51).

One of the first identified p53 downstream target genes is p21 (52). p53 is directly involved in the regulation of cell-cycle and apoptosis through target genes such as p21 and Bax $(52,53)$. Since the first discovery of direct p53 target genes, many downstream p53 target genes have been identified which expanded its biological role to involvement in DNA repair, senescence, aging, differentiation, cell adhesion, cell mobility, membrane functions, metabolism and autophagy (54). The most recently identified function is its involvement in stem-cell biology. Disruption of p53 enhanced the production of so-called induced pluripotent stem (iPS) cells (55-59).

Although p53 has been proven to be involved in many biological pathways, it is still not known how p53 selectively activates or represses a certain set of target genes to evoke a specific cellular response. The more we learn about p53 and its functions, the more complex the p53 response seems to be. This review will focus on the molecular mechanisms behind target gene selectivity of the transcription factor p53.

\section{Regulation of activity}

p53 regulates cell cycle arrest and apoptosis. When p53 is activated upon DNA damage it triggers a response to stop the cell cycle to allow the cells to take care of the DNA damage or, if DNA damage is too severe to be repaired, to target the cells for apoptosis to eliminate defective cells, which is crucial to prevent cancer. The molecular mechanisms to selectively evoke a specific cellular response, ranging from cell cycle arrest to apoptosis, remain widely elusive. Upon DNA damage transient alterations in cell cycle permit repair of DNA damage before the cell reinitiates replicative DNA synthesis (G1-arrest) or mitosis (G2-arrest). The G1-arrest is primarily regulated by $\mathrm{p} 21$, one of the most intensively studied direct p53 target genes since its discovery in $1993(52,60)$. p21 in turn inactivates cyclin $\mathrm{E} / \mathrm{Cdk} 2$ or cyclinD/Cdk4 resulting in hypophosphorylation of pRB and cell cycle arrest $(60,61)$. p53 also contributes to a $\mathrm{G} 2$ arrest by inducing transcription of GADD45, p21 and 14-3-3 $\sigma$ and by repressing cyclin B (61). Besides its involvement in cell cycle arrest, p53 can also induce DNA repair through multiple mechanisms. p53 can directly activate target genes which are involved in DNA repair such as p53R2 $(62,63)$, it can interact with proteins that function in DNA repair pathways such as replication protein A (RPA) (64) or directly with DNA (61).

When DNA damage is too severe to be repaired, p53 can induce apoptosis, the cell death program that is mediated by proteases called caspases. There are two distinct apoptotic signaling pathways; one responding to signals within the cells (the intrinsic pathway) and one responding to outside stress signals (the extrinsic pathway). p53 contributes to both pathways. It can activate the extrinsic pathway through induction of death ligands (65), such as FAS (66) and DR5 (67). The intrinsic pathway induces release of cytochrome C from mitochondria and is largely controlled by Bcl-2 proteins (68), in which $\mathrm{p} 53$ can activate pro-apoptotic $\mathrm{Bcl}-2$ proteins such as Bax (69), PUMA (70,71), Noxa (72) and Apaf-1 (73) and it represses anti-apoptotic $\mathrm{Bcl}-2$ proteins such as $\mathrm{Bcl}-2$ itself $(74,75)$ and Bcl-X (76). Both pathways result in the induction of caspase signaling, which induces apoptosis. Crosstalk between the two pathways also occurs. For example, caspase- 8 gets activated in the extrinsic pathway and can proteolytically activate Bid, which in turn facilitates cytochrome $\mathrm{C}$ release (77). Besides the two p53 transcriptionally-dependent apoptotic pathways, there is an alternative pathway in which p53 acts in a transcriptionally independent manner. In this pathway, p53 translocates to the mitochondria, where it directly acts with anti- and pro-apoptotic multidomain members of the Bcl-2 family to induce mitochondrial outer membrane permeabilization resulting in cell death $(23,78)$.

p53 can function as a transcription factor. The protein p53 functions mainly as a transcription factor. p53 interacts with DNA via its DNA binding domain. This domain has been defined by numerous biochemical studies and its interaction with DNA has been visualized by X-ray crystallography, which supported the hypothesis that DNA binding is critical for the biological activity of p53 (79-81). More than $90 \%$ of p53 mutations found in human tumors reside in the DNA binding domain. This implies the importance of the transcription factor function of p53 in growth control (82). Not only the DNA binding domain, but also the C-terminal part of p53 has been implicated in DNA binding (83). Besides the DNA binding domain, p53 consists of several other functional domains; transactivation domains, a proline-rich domain, a nuclear localization signaling domain and a tetramerization domain. The two tandem transactivation domains are located at the $\mathrm{N}$-terminal part of $\mathrm{p} 53$, which are responsible for activation or repression of target genes. Thus, p53 acts as a transcription factor mostly by sequence-specific binding to the DNA and thereby activating or repressing target genes to control cellular outcome.

Stabilization and activation of p53 by post-translational modifications. Numerous post-translational modifications (PTMs) of p53, such as phosphorylation, acetylation, methylation, ribosylation, neddylation, sumoylation and ubiquitination are involved in the stabilization and activation of p53 upon cellular stress (84-86).

One of the best studied post-translational modifications of p53 is its phosphorylation. Phosphorylation of p53 is involved in its stability as well as activity regulation. The phosphorylation sites are mostly clustered within the $\mathrm{N}$-terminal and C-terminal part of p53. p53 can be phosphorylated by several kinases, such as ATM, ATR, p38, Chk1 and Chk2. Phosphorylation close to the $\mathrm{N}$-terminus, the residues to which MDM2 binds, can interfere with the ability of MDM2 to bind to $\mathrm{p} 53$, such as phosphorylation of serine 15 (87). Phosphorylation of serine 15 by ATM and ATR can enhance the transcriptional activity of p53 (88). Phosphorylation of the C-terminus has been shown to be important for the activation 


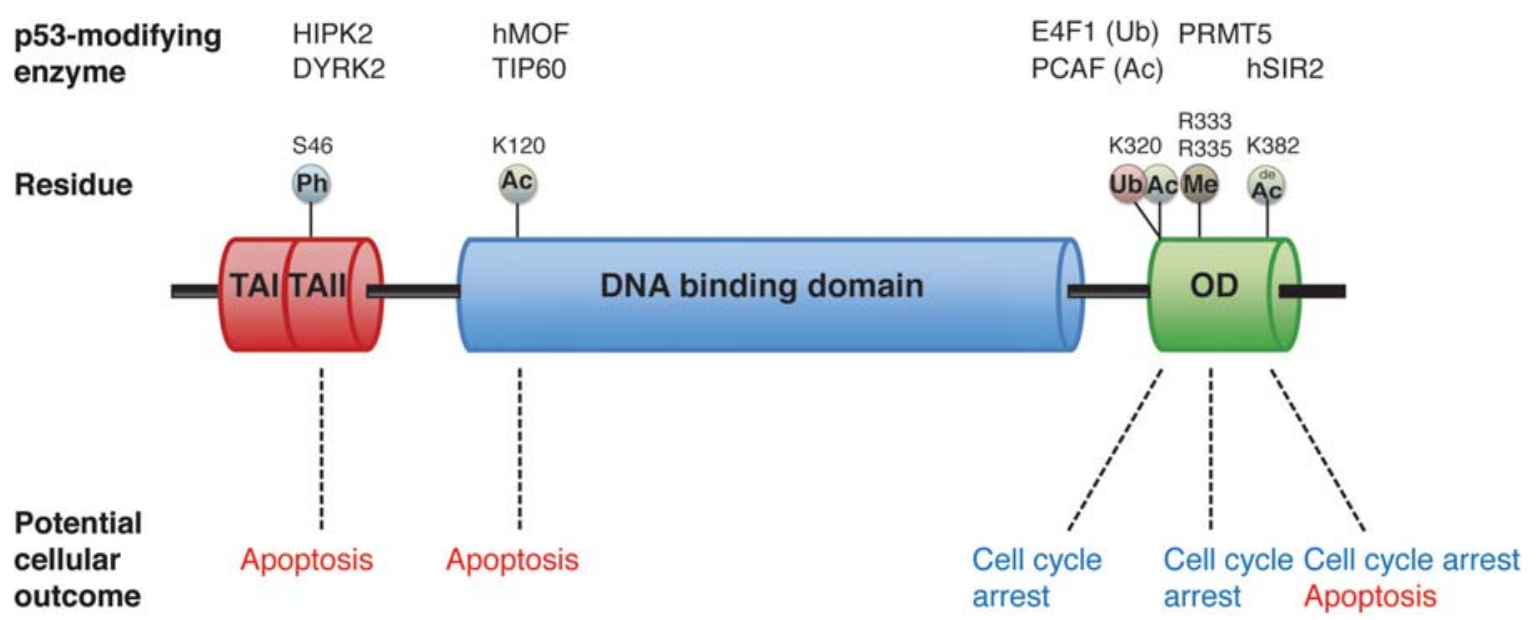

Figure 1. Post-translational modifications which play a role in target gene selection. The transcriptional activation domain I and II (TAI and TAII), DNAbinding domain (DBD) and oligomerization domain (OD) of p53 are indicated. Modified residues which are either phosphorylated (Ph), acetylated (Ac), ubiquitinated $(\mathrm{Ub})$, methylated $(\mathrm{Me})$ or deacetylated (deAc) and play a role in apoptosis or cell cycle arrest are depicted.

of the p53 protein (89). In principle, most phosphorylation events occur upon cellular stress and the patterns and kinetics of the phosphorylation marks can reflect the actual inducing stress signal. UV irradiation, for instance, induces specifically the phosphorylation of serine 392, whereas threonine 18 is mostly phosphorylated upon ionizing irradiation (90-92).

Also, the acetylation levels of p53 are significantly enhanced in response to stress and correlate well with p53 activation and stabilization (85). p53 is acetylated at several lysines by different histone acetyltransferases (HATs), such as p300 and Tip60 (93-95). Acetylation of the C-terminus activates p53's DNA binding. Knock-in studies in which the 6 C-terminal lysine residues were mutated to arginines (K6R), eliminating acetylation of these residues, reveal normal p53 protein stability before and after DNA damage, showing that these lysines are not solely responsible for efficient p53 degradation (96). However, different cells derived from these knock-in mice had an impaired p53-dependent target gene induction upon DNA-damage. Thus the post-translational modifications of these C-terminal residues of p53 are necessary for the proper p53 transactivation function as also seen in in vitro studies (97). Conversely, the activity of p53 can be regulated by deacetylation as well. Deacetylation complexes can contain HDAC1 (98), SIRT1 (99) or SIRT2 $\alpha$ (100) and can repress $\mathrm{p} 53$ transcriptional activation.

Lysine residues of p53 can also be methylated at least at three different sites by Smyd2 and Set8 and 9 (101-103). Furthermore, it was described for the first time that three arginine residues of p53 can be methylated as well (104). The lysine-specific demethylase LSD1 mediates p53 demethylation. This demethylation prevents p53 interaction with its coactivator 53BP1, thereby inhibiting p53 to induce apoptosis (105).

The mechanism to both stabilize and activate p53 is the competition for post-translational modifications on the same residue on $\mathrm{p} 53$. The $\mathrm{C}$-terminal lysine residues, which are important for ubiquitination for example, can also be acetylated. Acetylation of these residues blocks p53 degradation and stabilizes p53 $(106,107)$. Crosstalk between the different modifications also exists. Lysine methylation at K372 of p53 for example is important for subsequent acetylation of the
C-terminus, which results in stabilization of the protein (108). Furthermore, phosphorylation of p53 at serine 46 induces the acetylation of p53 at lysine 382 and happens upon severe DNA damage that leads to apoptosis $(109,110)$.

In conclusion, the stabilization and activation of p53 is regulated by numerous post-translational modifications. Although it has been shown that these are important for p53 regulation, the exact role of each modifications or the interplay between the modifications has not been shown yet.

\section{3. p53 target gene selection}

Post-translational modifications of p53 are important for target gene selection. Besides stabilization and activation, several post-translational modifications have been described to play a role in target gene selection (Fig. 1) $(54,86,111)$. Phosphorylation of serine 46 (S46) by HIPK2 $(109,110)$ or DYRK2 (112) is proposed to influence the induction of specific apoptotic target genes, such as p53 apoptosis inducing protein 1 (p53AIP1) in response to DNA damage (113-115). Phosphorylation of S46 is differentially regulated by a mechanism involving MDM2 depending on the extent of DNA damage (116). Upon mild DNA damage MDM2 ubiquitinates HIPK2, which is then unable to phosphorylate p53 at serine 46. Upon severe DNA damage, on the other hand, low levels of MDM2 do not ubiquitinate HIPK2 anymore and DYRK2 translocates to the nucleus. This results in phosphorylation of p53 at serine 46 which leads to the induction of specific apoptotic target genes triggering apoptosis $(112,116,117)$. Furthermore, the phosphorylation of serine 46 by HIPK 2 has also been reported to be necessary for a subsequent lysine 382 acetylation and both modifications have to be present for p53 transactivation of apoptotic target genes $(109,110,118)$. The serine 46 phosphorylation site can be regulated by several other kinases besides DYRK2 and HIPK2; protein kinase $\mathrm{C} \delta$ (PKC ) (119), AMP-activated protein kinase catalytic subunit $\alpha(\mathrm{AMPK} \alpha)(120)$ or p38 mitogen-activated protein kinase (p38 MAPK) (121). The fact that several kinases can phosphorylate serine 46 suggests that this is a very important site for the regulation and function of p53 whereas the exact 


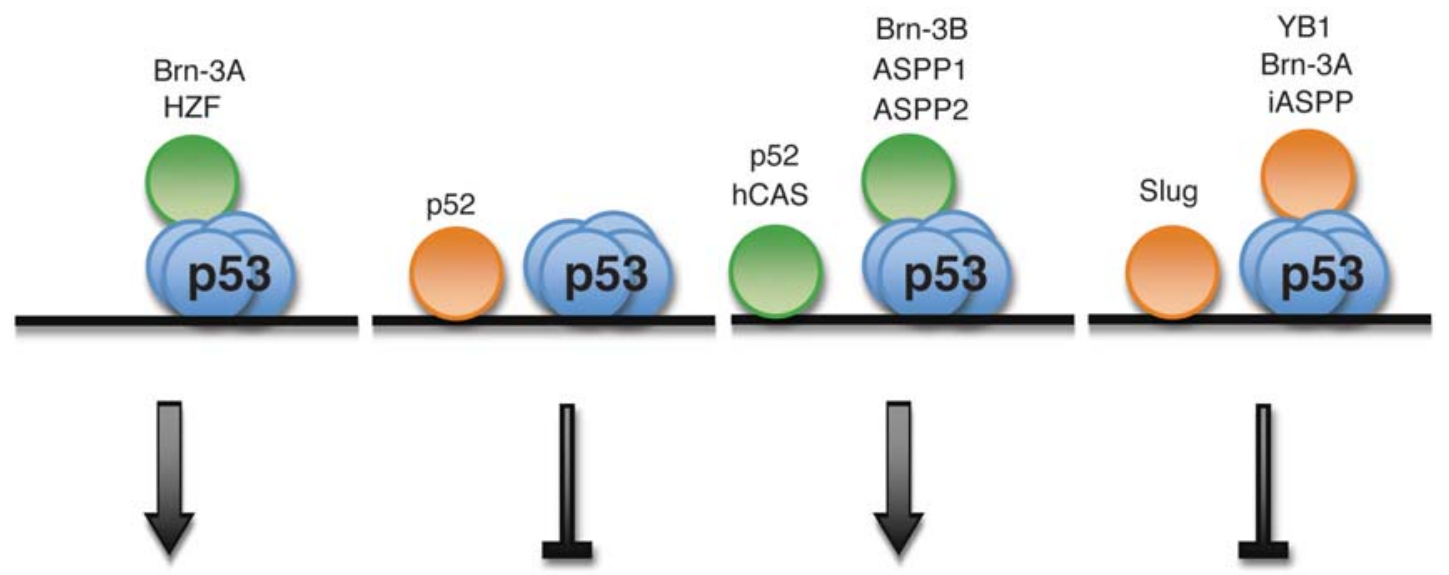

\section{Cell cycle arrest}

\section{Apoptosis}

Figure 2. Proteins that influence cellular outcome. Proteins which either bind to p53 directly or act as a co-factor can either enhance (depicted in green) or block (depicted in orange) the p53 stress response resulting in cell cycle arrest or apoptosis.

regulation of this site with respect to the selectivity of the p53transcriptional program remains to be further elucidated.

Acetylation of lysine 120 (K120) of p53 upon DNA damage by two MYST family histone acetyl transfereases (HATs) hMOF and Tip60 has also been shown to promote apoptosis $(95,122)$. p53 that is acetylated at K120 was reported to accumulate preferentially on the promoters of pro-apoptotic target genes, such as Bax and PUMA, suggesting that this modification can modulate p53 target gene selection $(95,122)$. In human cancers a p53 mutation can occur at K120 in which K120 is mutated to an arginine. This mutated form of p53 can no longer be post-translationally modified at this site. The mutation diminishes the p53-mediated apoptosis without effecting cell cycle arrest, p53 stability or DNA binding $(95,122)$.

Lysine 320 (K320) on the other hand, can be modified independently by both ubiquitination and acetylation to influence promoter selectivity. The p300/CBP-associated factor (PCAF) acetylates p53 at K320 $(94,123)$. Acetylation of p53 K320 was shown to favor DNA binding to the p21 target gene, promoting cell survival and cell cycle arrest after DNA damage (124). The E3 ligase E4F1 ubiquitinates p53 also at $\mathrm{K} 320$ and this increases the activation of cell cycle arrest genes, such as p21 and cyclin G1 as well (125). In vivo knockin mice with a lysine to arginine mutation (p53K317R) corresponding to K320 in human, abolished DNA damageinduced acetylation at position 317 , resulting in increased p53-dependent apoptosis. Several apoptotic target genes such as PUMA and Noxa were upregulated in thymocytes from $\mathrm{p} 53^{\mathrm{K} 317 \mathrm{R}}$ mice compared to wild-type mice demonstrating that acetylation of this residue negatively regulates p53 apoptotic activity after DNA damage (126).

Acetylation of p53 by p300 generally induces its proapoptotic activity (124). As mentioned before, acetylation appears to depend to some extent on phosphorylation: S46 phosphorylation induces the acetylation of p53 at lysine 382 (110). Furthermore, RNAi mediated knockdown of Chk1 and Chk2, which both induce C-terminal phosphorylation of p53, reduced acetylation greatly (127). Interestingly, acetylation of p53 at carboxy-terminal lysine residues, lysine 320, 373 and 382 , have also been reported to be required for its transcriptionindependent apoptotic function (128). Not only acetylation but also deacetylation of p53 is involved in p53 target gene selection. hSIR2/SIRT1 deacetylates p53 at lysine 382 which can decrease the p53 transcriptional activity at the p21 promoter, whereas in other cellular contexts it can repress p53 function in apoptosis $(99,100)$.

Recently, it was reported that the protein arginine methyltransferase 5 (PRMT5) is responsible for the p53 methylation at arginine residues 333 and 335 (104). PRMT5 appears to be essential for cell proliferation and PRMT5 deficiency triggers G1 cell cycle arrest (129). PRMT5 is also described to be required for p53 expression itself and for the induction of the p53 targets MDM2 and p21 upon DNA damage (129).

While new p53 modifications continue to be uncovered, the impact of single modifications or a combination of all those modifications on p53 outcome and cellular functions remains to be elucidated.

p53 co-factors and binding proteins involved in p53-mediated transcription. For the p53-mediated transcription several protein complexes are required. Transcriptional co-factors and p53-binding proteins are essential for the regulation of the transcriptional activities of p53 (54,130). An important general activator of p53 is p300. p300 acts as a p53 co-activator for p53 target genes by acetylating p53 $(93,131)$. The activity of p300 is tightly regulated by p300 co-factors, which enhance or repress the p53 response. Two co-recruited factors, junctionmediating and regulatory protein (JMY) and stress responsive activator of p300 (Strap) are also required for general p53 activation $(132,133)$. A third p300 cofactor, S phase kinaseassociated protein 2 (SKP2), on the other hand, has been reported to be involved in the selectivity of the p53 response. SKP2 prevents the interaction between p300 and p53, resulting in suppression of apoptosis (134). Furthermore, several 
chromatin modifying proteins are essential for p53 transcriptional regulation. The chromatin-modifying and remodeling proteins BRG1 and hSNF5 enhance p53-dependent gene transcription $(135,136)$. The STAGA complex, a multiprotein complex with the acetyltransferase GCN5L as the catalytic subunit, acts as a coactivator of p53, in which p53 interacts with SAGA subunits GCN5, ADA2b and TAF9 (137). The ATM-related TRAPP protein is recruited by $\mathrm{p} 53$ to activate gene transcription (138).

Besides the proteins that are general activators or repressors of p53 there are proteins that can particularly influence p53 target gene selectivity or cellular outcome (Fig. 2). Among the p53-binding proteins that influence the cellular outcome are the apoptosis-stimulating proteins of the ASPP family, which consist of the two pro-apoptotic members ASPP1 and ASPP2 and the anti-apoptotic member iASPP $(139,140)$. ASPP1 and ASPP2 bind to the DNA-binding domain of p53 and specifically modulate p53-induced apoptosis by stimulating p53 binding to the Bax and PIG3 genes, whereas iASPP inhibits p53-mediated apoptosis but not cell cycle arrest, which implies that iASPP competes with ASPP1 and ASPP2 for binding with $\mathrm{p} 53$, but the exact mechanism is currently unknown. Downregulation of iASPP enhances the binding of p53 to the Bax promoter, but not to the p21 promoter (141). The hematopoietic zinc finger protein $(\mathrm{HZF})$ is induced by p53 and binds to the DNA-binding domain of p53 (142). It facilitates p53-binding to cell cycle arrest target genes such as p21 and 14-3-30 resulting in preferential cell cycle arrest.

The Brn3 family of POU domain transcription factors binds to the p53-binding domain (143). While Brn-3a cooperates with p53 to activate p21 and repress Bax expression, Brn-3b has opposing effects. A recently identified p53-binding protein Krüppel-associated box (KRAB)-type zinc-finger Apak is a negative regulator of p53-mediated apoptosis (144). Apak binds directly to p53 in unstressed cells which results in downregulation of pro-apoptotic genes, such as BAX and Puma, probably through recruitment of HDAC1complexes to p53 and thereby reducing p53 acetylation. In response to stress Apak is phosphorylated and dissociates from p53, resulting in induction of apoptosis (144). The Y-box-binding protein YB1 interacts with p53 and inhibits the ability of p53 to induce apoptosis, but does not interfere with the p53 activation of p21 to induce cell cycle arrest (145). Binding of the co-factor human cellular apoptosis susceptibility protein (hCAS/CSE1L) to a subset of p53 target genes, such as PIG3, has been shown to positively influence the p53mediated apoptosis (146). The co-repressor CtBP2 reduces p53-dependent transcription of Bax, but not of p21 $(147,148)$. The p52 NF-кB subunit can either cooperate or antagonize with p53 to regulate target genes by regulating coactivator and corepressor recruitment (149). p52 represses p21 expression, but cooperates with p53 to increase PUMA, DR5 and GADD45.

Slug is a transcription factor and a p53 target gene, which plays a role in repressing p53-mediated apoptosis by antagonizing p53-mediated transactivation of PUMA (150). Similarly, the p53 target gene IRF2BP2 increases the threshold for the induction of apoptosis (151). IRF2BP2 inhibits p53 transactivation of p21 and Bax, but upon higher levels of $\mathrm{p} 53$, inhibition of Bax transactivation could be overcome.
The newly discovered p53 target gene XEDAR on the other hand (152), is a p53 target gene that seems to lower the apoptotic threshold, but the molecular mechanism is not known yet. Besides its involvement in apoptosis-regulation XEDAR is also involved in the anoikis pathway (152).

Since post-translational modifications (PTMs), p53-binding proteins and co-factors are all involved in p53 target regulation, it is likely that crosstalk between PTMs and p53-binding protein or co-factors occurs. An example of this interplay is the p53 binding protein peptidyl-prolyl cis/trans isomerase (Pin1). Pin 1 regulates conformational changes of certain phosphorylated proteins. Upon DNA damage Pin1 recognizes Serine 46 phosphorylation of p53 and mediates p53 dissociation from iASPP, thereby promoting apoptosis (153). Future research should elucidate how p53 PTMs influence the interaction with p53-binding proteins and co-factors and what result this has on p53 target gene selectivity. Possibly p53-binding proteins or co-factors interactions are regulated by PTMs of p53 and/or interacting proteins promote changes in 553 PTMs to achieve promoter specific transactivation.

Thus, there are various p53-binding proteins and co-factors, which are required for regulation of the transcriptional activities of p53 either as general activators or repressors of p53, or as proteins that are involved in target gene selectivity. Among those, some are also direct p53 target genes. Although they do not necessarily show a direct interaction with p53, they can form regulatory loops, thereby influencing p53-directed cell cycle arrest or apoptosis. Although it is known for many p53-binding proteins and co-factors that they influence p53directed cellular outcome, most of the time the effect is only tested on selected p53 target genes and therefore the complete molecular mechanism how p53 directs cellular outcome is still elusive.

Additional layers of p53 gene regulation. In addition to p53binding proteins and co-factors that influence the p53 target gene regulation, the p53-family members p63 and p73 can contribute to the p53 cellular outcome (154-156). p63 and p73 were reported to be required for the p53-binding to the p53 response elements of the target genes Perp, Bax and Noxa, but not to those of p21 or MDM2 (155). A 'priming model' was suggested, in which p63 and p73 can bind to a specific chromatin-embedded response element not accessible for p53, and subsequently modify the context of the response element in such a way that it becomes available for p53 binding (111). However, the fact that p63 and p73 are required for p53-dependent apoptosis might not be the case for all cell-types, since studies performed in T-cells showed that p63 and p73 were dispensable for p53-dependent apoptosis of T-cells (157). ChIP-on-chip data showed that the full-length proteins TAp63 and TAp73 can bind to a large amount of p53 binding sites and could thereby play an important role in target gene regulation (158). The $\Delta \mathrm{N}$ isoforms of p63 and p73, lacking the transactivation domain, compete with p53 for binding sites and behave as repressors of the p53 target gene response (159). Not only the p53 family members p63 and p73 consist of multiple isoforms, but p53 as well (160). These p53 isoforms can play a role in target gene regulation. The isoform p53ß, for example, binds to p53 binding sites and can enhance p53 target gene expression 
(160). ChIP performed with a specific $\mathrm{p} 53 ß$ antibody showed that $\mathrm{p} 53 \mathrm{~B}$ binds preferentially to the $\mathrm{p} 21$ and Bax promoter but not to the one of MDM2. Thus, also p53 isoforms and its family members p63 and p73 can play an important role in target gene regulation.

Another layer of regulation of target gene expression is likely mediated by p53-regulated miRNAs. The first miRNA family which was identified to be p53 responsive was miR-34 $(161,162)$. miR-34a is a transcriptional target of p53 and induces apoptosis. It inhibits SIRT1, which regulates p53dependent apoptosis through deacetylation and stabilization of p53 (163). Thus, a positive feedback loop exists in which p53 induces expression of miR-34a, which in turn suppresses SIRT1, resulting in increasing p53 activity (163). Other identified p53 responsive miRNAs are the miR192/194 and miR-194/215 clusters, (164-166). Whereas miR-34a is involved in inducing apoptosis, miR-192 induces cell cycle arrest in a p53-dependent fashion (166). Furthermore, a new function of p53 in regulating cell cycle arrest involving miRNAs has been recently identified. p53 interacts with proteins of the Drosha complex, which promotes processing of a subset of miRNAs with growth-suppressive function, including miR16-1, miR-143 and miR-145 (167). Thus, by processing of these miRNA cells go into cell cycle arrest, which is a new function how p53 can inhibt cellular growth.

Altogether, many layers of p53 target gene regulation are required to regulate the p53 target response and we still have to learn much more about the cellular decision process.

Current state-of-the-art techniques to elucidate p53 target gene regulation. Gene expression is not only regulated by binding of a single transcription factor to a single binding site at a given time point, but by a combination of cis-acting regulatory sequences and trans-acting factors or post-transcriptional regulation as well (168). Uncovering locations of transcription factor binding sites and regulatory elements is critical for the importance of understanding the genome-wide dynamic view how these factors regulate gene expression. Since the publication of the human genome sequence $(169,170)$, a great effort has been made to elucidate transcriptional circuits that control gene expression in the whole human genome. Chromatin immunoprecipitation (ChIP) is a robust method to identify protein-DNA interactions in chromatin. Essentially, DNA-binding proteins are crosslinked to DNA and cells are lysed and fragmented. Fragments bound by the protein of interest are immunoprecipitated and those enriched DNA fragments can either be checked whether they include a specific gene locus or they can be mapped in a genome-wide manner using different ChIP-based techniques. In 2000, the first study to detect genome-wide binding sites combining ChIP with microarrays (ChIP-on-chip) was reported for genespecific transcription activators in yeast (171). Technological advances have enabled high throughput sequencing of the immunoprecipitated DNA fragments. Massive parallel sequencing of ChIP-DNA fragments (ChIP-seq) allows identification of binding sites with greater sensitivity and resolution than ever before (172). Massive parallel sequencing has multiple applications. For example, the transcriptional landscape can be studied on the basis of gene expression by direct sequencing of cDNA (RNA-seq). RNA-seq not only provides information about alternative splicing and different promoter usage, but also allows to identify transcripts that are expressed on low levels, something which was not possible with expression microarrays before.

Several studies have identified p53 binding sites using a variety of ChIP-based techniques (158,173-181). Cawley and co-workers were the first to identify p53 binding sites using tiling microarrays representing chromosome 21 and 22 (173). Based on p53 binding to chromosome 21 and 22 they estimated 1600 binding sites for p53 in the whole human genome. In 2006 Wei et al (176) identified 542 global high-confidence binding loci by combining ChIP with paired-end ditag (PET) sequencing. The genome-wide set of p53 binding sites was expanded by Smeenk et al using ChIP-on-chip identifying 1546 genome-wide high confidence binding sites (158). With the generated data using genome-wide binding techniques new bioinformatic analysis can be performed. In 1992, the p53 binding site has been characterized and described as two copies of the palindromic consensus half-site RRRCWWGYYY, in which $\mathrm{R}=$ purine, $\mathrm{W}=\mathrm{A}$ or $\mathrm{T}$ and $\mathrm{Y}=$ pyrimidine, with a spacer of $0-13 b p(15,182)$. In 2002, an algorithm (p53MH) was developed based on 37 known p53 binding sites (183). The identification of genome-wide binding sites allowed the development of a more accurate p53 motif finding algorithm of the identified p53 binding sites (p53scan) (158). This showed that the p53 motif is found in $~ 80 \%$ of all binding sites. Both genome-wide ChIP-PET and ChIP-on-ChIP data showed that in most of the p53 binding sites no spacer is present $(158,176)$. Based on the genome-wide data novel aspects of p53 functions could be identified $(158,176)$, and subsequently also clinical relevance was shown by validating target gene response to p53 activation in clinical breast tumors (176). Although a variety of cell lines and treatments were used, many binding sites overlap between the different studies, as up to $69 \%$ of the p53 binding sites in the PET5 cluster identified by Wei et al (176) were also bound by the set identified by Smeenk et al (158). Besides genome-wide binding sites for $\mathrm{p} 53$, binding sites for p53 family members p63 and p73 have also been identified $(158,177,184)$. Not only the p53 binding sites overlap to a large extend in different cells and/or treatments, but also within its family members p63 and p73 (158). Whereas microarray data identified many new p53 regulated target genes $(185,186)$, genome-wide p53 binding data combined with expression data can show direct involvement of p53 binding to a target gene and therefore helps to understand the genome-wide dynamic view how p53 regulates gene expression.

\section{Future outlook}

Gene expression regulation is dynamic and thereby very complex. Most likely different cellular outcomes cannot be explained on the basis of selective binding of p53 only. Therefore, it is likely that additional levels of regulation, such as post-translational modifications of p53, co-factors, p53 binding factors, p53 responsive microRNAs (miRNAs), p53 family members or chromatin remodeling factors, mediate target gene expression. Until now, most studies indicating involvement of for example a certain p53 PTM or particular cofactor in target gene expression, have been performed on 
the basis of a selected set of target genes. The next step in unraveling the p53 target gene choice will be to combine genome-wide p53 binding data with its PTMs, co-factors, binding proteins, and histone modifications to verify this hypothesis. A combination of for example ChIP-seq with RNA-seq at multiple time-points after multiple treatments in different cells makes it possible to provide insight into the genome-wide dynamic view of gene regulation. Tiling micorarrays containing $30 \mathrm{Mb}$ of the human genome have already started to link p53 binding sites to histone modifications in the human genome (174) and it is possible to do this in a genome-wide approach. Furthermore, by combining ChIP-seq not only with expression data from for example RNA-seq or chromatin modifications, but also with other techniques such as mass spectrometry, target genes affected by specific co-factor interactions could give more insight into p53 target gene selection (146). Thus, this new era of massive parallel sequencing has made it possible to analyze on a global scale how p53, in combination with cis-acting regulatory sequences and trans-acting factors, can regulate gene expression. Future p53 studies using massive parallel sequencing and profound data and network analysis will provide further insight into the molecular mechanism behind target gene selectivity of the transcription factor p53.

\section{Acknowledgements}

We thank Max Koeppel, Daniela Kramer and Bianca Gilbert for critically reading the manuscript. Funding for this work was provided by the Dutch Cancer Foundation (KWF) (KUN 2003-2926 and KUN 2005-3347 to L.S.) and by the Netherlands Organisation for Scientific Research (NWO) (Vidi 846.05.002 to M.L.).

\section{References}

1. Lane DP and Crawford LV: T antigen is bound to a host protein in SV40-transformed cells. Nature 278: 261-263, 1979.

2. Linzer DI and Levine AJ: Characterization of a $54 \mathrm{~K}$ dalton cellular SV40 tumor antigen present in SV40-transformed cells and uninfected embryonal carcinoma cells. Cell 17: 43-52, 1979.

3. DeLeo AB, Jay G, Appella E, Dubois GC, Law LW and Old LJ: Detection of a transformation-related antigen in chemically induced sarcomas and other transformed cells of the mouse. Proc Natl Acad Sci USA 76: 2420-2424, 1979.

4. Eliyahu D, Raz A, Gruss P, Givol D and Oren M: Participation of p53 cellular tumour antigen in transformation of normal embryonic cells. Nature 312: 646-649, 1984.

5. Jenkins JR, Rudge K and Currie GA: Cellular immortalization by a cDNA clone encoding the transformation-associated phosphoprotein p53. Nature 312: 651-654, 1984.

6. Parada LF, Land H, Weinberg RA, Wolf D and Rotter V: Cooperation between gene encoding p53 tumour antigen and ras in cellular transformation. Nature 312: 649-651, 1984.

7. Eliyahu D, Michalovitz D, Eliyahu S, Pinhasi-Kimhi O and Oren M: Wild-type p53 can inhibit oncogene-mediated focus formation. Proc Natl Acad Sci USA 86: 8763-8767, 1989.

8. Finlay CA, Hinds PW and Levine AJ: The p53 proto-oncogene can act as a suppressor of transformation. Cell 57: 1083-1093, 1989.

9. Hinds P, Finlay $\mathrm{C}$ and Levine AJ: Mutation is required to activate the p53 gene for cooperation with the ras oncogene and transformation. J Virol 63: 739-746, 1989.

10. Hollstein M, Sidransky D, Vogelstein B and Harris CC: p53 mutations in human cancers. Science 253: 49-53, 1991.

11. Levine AJ, Momand J and Finlay CA: The p53 tumour suppressor gene. Nature 351: 453-456, 1991
12. Malkin D, Li FP, Strong LC, et al: Germ line p53 mutations in a familial syndrome of breast cancer, sarcomas, and other neoplasms. Science 250: 1233-1238, 1990.

13. Srivastava S, Zou ZQ, Pirollo K, Blattner W and Chang EH: Germ-line transmission of a mutated p53 gene in a cancer-prone family with Li-Fraumeni syndrome. Nature 348: 747-749, 1990.

14. Donehower LA, Harvey M, Slagle BL, et al: Mice deficient for p53 are developmentally normal but susceptible to spontaneous tumours. Nature 356: 215-221, 1992.

15. El-Deiry WS, Kern SE, Pietenpol J, Kinzler KW and Vogelstein B: Definition of a consensus binding site for p53. Nat Genet 1: 45-49, 1992.

16. Funk WD, Pak DT, Karas RH, Wright WE and Shay JW: A transcriptionally active DNA-binding site for human $\mathrm{p} 53$ protein complexes. Mol Cell Biol 12: 2866-2871, 1992.

17. Raycroft L, Wu HY and Lozano G: Transcriptional activation by wild-type but not transforming mutants of the p53 antioncogene. Science 249: 1049-1051, 1990.

18. Fields S and Jang SK: Presence of a potent transcription activating sequence in the p53 protein. Science 249: 1046-1049, 1990.

19. Kern SE, Kinzler KW, Bruskin A, et al: Identification of p53 as a sequence-specific DNA-binding protein. Science 252: 1708-1711, 1991

20. Bargonetti J, Friedman PN, Kern SE, Vogelstein B and Prives C: Wild-type but not mutant p53 immunopurified proteins bind to sequences adjacent to the SV40 origin of replication. Cell 65: 1083-1091, 1991

21. Yonish-Rouach E, Resnitzky D, Lotem J, Sachs L, Kimchi A and Oren M: Wild-type p53 induces apoptosis of myeloid leukaemic cells that is inhibited by interleukin-6. Nature 352: 345-347, 1991

22. Kastan MB, Zhan Q, el-Deiry WS, et al: A mammalian cell cycle checkpoint pathway utilizing p53 and GADD45 is defective in ataxia-telangiectasia. Cell 71: 587-597, 1992.

23. Moll UM, Wolff S, Speidel D and Deppert W: Transcriptionindependent pro-apoptotic functions of p53. Curr Opin Cell Biol 17: 631-636, 2005.

24. Momand J, Zambetti G, Olson DC, George DL and Levine AJ: The mdm-2 oncogene product forms a complex with the p53 protein and inhibits p53-mediated transactivation. Cell 69: 1237-1245, 1992

25. Barak Y and Oren M: Enhanced binding of a $95 \mathrm{kDa}$ protein to p53 in cells undergoing p53-mediated growth arrest. EMBO J 11: 2115-2121, 1992.

26. Chen J, Marechal V and Levine AJ: Mapping of the p53 and mdm-2 interaction domains. Mol Cell Biol 13: 4107-4114, 1993.

27. Barak Y, Juven T, Haffner R and Oren M: mdm2 expression is induced by wild type p53 activity. EMBO J 12: 461-468, 1993.

28. Juven T, Barak Y, Zauberman A, George DL and Oren M: Wild type p53 can mediate sequence-specific transactivation of an internal promoter within the mdm2 gene. Oncogene 8: 3411-3416, 1993.

29. Wu X, Bayle JH, Olson D and Levine AJ: The p53-mdm-2 autoregulatory feedback loop. Genes Dev 7: 1126-1132, 1993.

30. Haupt Y, Maya R, Kazaz A and Oren M: Mdm2 promotes the rapid degradation of p53. Nature 387: 296-299, 1997.

31. Kubbutat MH, Jones SN and Vousden KH: Regulation of p53 stability by Mdm2. Nature 387: 299-303, 1997.

32. Li M, Brooks CL, Wu-Baer F, Chen D, Baer R and Gu W: Monoversus polyubiquitination: differential control of p53 fate by Mdm2. Science 302: 1972-1975, 2003.

33. Jones SN, Roe AE, Donehower LA and Bradley A: Rescue of embryonic lethality in Mdm2-deficient mice by absence of $\mathrm{p} 53$. Nature 378: 206-208, 1995.

34. Montes de Oca Luna R, Wagner DS and Lozano G: Rescue of early embryonic lethality in mdm2-deficient mice by deletion of p53. Nature 378: 203-206, 1995.

35. Shvarts A, Steegenga WT, Riteco N, et al: MDMX: a novel p53-binding protein with some functional properties of MDM2. EMBO J 15: 5349-5357, 1996.

36. Badciong JC and Haas AL: MdmX is a RING finger ubiquitin ligase capable of synergistically enhancing Mdm2 ubiquitination. J Biol Chem 277: 49668-49675, 2002.

37. Kawai H, Lopez-Pajares V, Kim MM, Wiederschain D and Yuan Z-M: RING domain-mediated interaction is a requirement for MDM2's E3 ligase activity. Cancer Res 67: 6026-6030, 2007. 
38. Migliorini D, Lazzerini Denchi E, Danovi D, et al: Mdm4 (Mdmx) regulates p53-induced growth arrest and neuronal cell death during early embryonic mouse development. Mol Cell Biol 22: 5527-5538, 2002.

39. Parant J, Chavez-Reyes A, Little NA, et al: Rescue of embryonic lethality in Mdm4-null mice by loss of Trp53 suggests a nonoverlapping pathway with MDM2 to regulate p53. Nat Genet 29: 92-95, 2001.

40. Brooks CL and Gu W: New insights into p53 activation. Cell Res 20: 614-621, 2010.

41. Bothner B, Lewis WS, DiGiammarino EL, Weber JD, Bothner SJ and Kriwacki RW: Defining the molecular basis of Arf and Hdm2 interactions. J Mol Biol 314: 263-277, 2001

42. Bernardi R, Scaglioni PP, Bergmann S, Horn HF, Vousden KH and Pandolfi PP: PML regulates p53 stability by sequestering Mdm2 to the nucleolus. Nat Cell Biol 6: 665-672, 2004.

43. Chen D, Zhang Z, Li M, et al: Ribosomal protein S7 as a novel modulator of p53-MDM2 interaction: binding to MDM2, stabilization of p53 protein, and activation of p53 function Oncogene 26: 5029-5037, 2007.

44. Dai M-S, Zeng SX, Jin Y, Sun X-X, David L and Lu H: Ribosomal protein L23 activates p53 by inhibiting MDM2 function in response to ribosomal perturbation but not to translation inhibition. Mol Cell Biol 24: 7654-7668, 2004.

45. Jin A, Itahana K, O'Keefe K and Zhang Y: Inhibition of HDM2 and activation of p53 by ribosomal protein L23. Mol Cell Biol 24: 7669-7680, 2004.

46. Kurki S, Peltonen K, Latonen L, et al: Nucleolar protein NPM interacts with HDM2 and protects tumor suppressor protein p53 from HDM2-mediated degradation. Cancer Cell 5: 465-475, 2004.

47. Lohrum MAE, Ludwig RL, Kubbutat MHG, Hanlon M and Vousden KH: Regulation of HDM2 activity by the ribosomal protein L11. Cancer Cell 3: 577-587, 2003.

48. Dornan D, Wertz I, Shimizu H, et al: The ubiquitin ligase COP1 is a critical negative regulator of p53. Nature 429: 86-92, 2004.

49. Leng RP, Lin Y, Ma W, et al: Pirh2, a p53-induced ubiquitinprotein ligase, promotes p53 degradation. Cell 112: 779-791, 2003.

50. Chen D, Kon N, Li M, Zhang W, Qin J and Gu W: ARF-BP1/ Mule is a critical mediator of the ARF tumor suppressor. Cell 121: 1071-1083, 2005

51. Li M, Chen D, Shiloh A, et al: Deubiquitination of p53 by HAUSP is an important pathway for p53 stabilization. Nature 416: 648-653, 2002.

52. El-Deiry WS, Tokino T, Velculescu VE, et al: WAF1, a potential mediator of p53 tumor suppression. Cell 75: 817-825, 1993.

53. Miyashita T, Krajewski S, Krajewska M, et al: Tumor suppressor p53 is a regulator of bcl-2 and bax gene expression in vitro and in vivo. Oncogene 9: 1799-1805, 1994.

54. Vousden $\mathrm{K}$ and Prives C: Blinded by the light: The growing complexity of p53. Cell 137: 413-431, 2009.

55. Hong H, Takahashi K, Ichisaka T, et al: Suppression of induced pluripotent stem cell generation by the $\mathrm{p} 53-\mathrm{p} 21$ pathway. Nature 460: 1132-1135, 2009

56. Kawamura T, Suzuki J, Wang YV, et al: Linking the p53 tumour suppressor pathway to somatic cell reprogramming. Nature 460: 1140-1144, 2009.

57. Li H, Collado M, Villasante A, et al: The Ink4/Arf locus is a barrier for iPS cell reprogramming. Nature 460: 1136-1139, 2009.

58. Marión RM, Strati K, Li H, et al: A p53-mediated DNA damage response limits reprogramming to ensure iPS cell genomic integrity. Nature 460: 1149-1153, 2009.

59. Utikal J, Polo JM, Stadtfeld M, et al: Immortalization eliminates a roadblock during cellular reprogramming into iPS cells. Nature 460: 1145-1148, 2009

60. Harper JW, Adami GR, Wei N, Keyomarsi K and Elledge SJ: The p21 Cdk-interacting protein Cip1 is a potent inhibitor of G1 cyclin-dependent kinases. Cell 75: 805-816, 1993.

61. Stewart ZA and Pietenpol J: p53 signaling and cell cycle checkpoints. Chem Res Toxicol 14: 243-263, 2001.

62. Tanaka H, Arakawa H, Yamaguchi T, et al: A ribonucleotide reductase gene involved in a p53-dependent cell-cycle checkpoint for DNA damage. Nature 404: 42-49, 2000.

63. Nakano K, Bálint E, Ashcroft $\mathrm{M}$ and Vousden KH: A ribonucleotide reductase gene is a transcriptional target of p53 and p73. Oncogene 19: 4283-4289, 2000.

64. Abramova NA, Russell J, Botchan M and Li R: Interaction between replication protein A and p53 is disrupted after UV damage in a DNA repair-dependent manner. Proc Natl Acad Sci USA 94: 7186-7191, 1997.
65. Ashkenazi A and Dixit VM: Death receptors: signaling and modulation. Science 281: 1305-1308, 1998.

66. Owen-Schaub LB, Zhang W, Cusack JC, et al: Wild-type human p53 and a temperature-sensitive mutant induce Fas/APO-1 expression. Mol Cell Biol 15: 3032-3040, 1995.

67. Wu GS, Burns TF, McDonald ER, et al: KILLER/DR5 is a DNA damage-inducible p53-regulated death receptor gene. Nat Genet 17: 141-143, 1997.

68. Cory S and Adams JM: The Bcl2 family: regulators of the cellular life-or-death switch. Nat Rev Cancer 2: 647-656, 2002.

69. Miyashita T and Reed JC: Tumor suppressor p53 is a direct transcriptional activator of the human bax gene. Cell 80: 293-299, 1995.

70. Nakano K and Vousden KH: PUMA, a novel proapoptotic gene, is induced by p53. Mol Cell 7: 683-694, 2001.

71. Yu J, Zhang L, Hwang PM, Kinzler KW and Vogelstein B: PUMA induces the rapid apoptosis of colorectal cancer cells. Mol Cell 7: 673-682, 2001.

72. Oda E, Ohki R, Murasawa H, et al: Noxa, a BH3-only member of the Bcl-2 family and candidate mediator of p53-induced apoptosis. Science 288: 1053-1058, 2000.

73. Robles AI, Bemmels NA, Foraker AB and Harris CC: APAF-1 is a transcriptional target of p53 in DNA damage-induced apoptosis. Cancer Res 61: 6660-6664, 2001.

74. Haldar S, Negrini M, Monne M, Sabbioni S and Croce CM: Down-regulation of bcl-2 by p53 in breast cancer cells. Cancer Res 54: 2095-2097, 1994.

75. Miyashita T, Harigai M, Hanada M and Reed JC: Identification of a p53-dependent negative response element in the bcl-2 gene. Cancer Res 54: 3131-3135, 1994.

76. Sugars KL, Budhram-Mahadeo VS, Packham G and Latchman DS: A minimal Bcl-x promoter is activated by Brn3a and repressed by p53. Nucleic Acids Res 29: 4530-4540, 2001.

77. Green DR: Apoptotic pathways: paper wraps stone blunts scissors. Cell 102: 1-4, 2000.

78. Vaseva AV and Moll UM: The mitochondrial p53 pathway. Biochim Biophys Acta 1787: 414-420, 2009

79. Cho Y, Gorina S, Jeffrey PD and Pavletich NP: Crystal structure of a p53 tumor suppressor-DNA complex: understanding tumorigenic mutations. Science 265: 346-355, 1994.

80. Ho WC, Fitzgerald MX and Marmorstein R: Structure of the p53 core domain dimer bound to DNA. J Biol Chem 281: 20494-20502, 2006.

81. Kitayner M, Rozenberg H, Kessler N, et al: Structural basis of DNA recognition by p53 tetramers. Mol Cell 22: 741-753, 2006.

82. Hainaut P and Hollstein M: p53 and human cancer: the first ten thousand mutations. Adv Cancer Res 77: 81-137, 2000.

83. Ayed A, Mulder FA, Yi GS, Lu Y, Kay LE and Arrowsmith CH: Latent and active p53 are identical in conformation. Nat Struct Biol 8: 756-760, 2001

84. Bode A and Dong Z: Post-translational modification of p53 in tumorigenesis. Nat Rev Cancer 4: 793-805, 2004.

85. Brooks CL and Gu W: Ubiquitination, phosphorylation and acetylation: the molecular basis for $\mathrm{p} 53$ regulation. Curr Opin Cell Biol 15: 164-171, 2003.

86. Olsson A, Manzl C, Strasser A and Villunger A: How important are post-translational modifications in p53 for selectivity in target-gene transcription and tumour suppression? Cell Death Differ 14: 1561-1575, 2007.

87. Shieh SY, Ikeda M, Taya Y and Prives C: DNA damage-induced phosphorylation of $\mathrm{p} 53$ alleviates inhibition by MDM2. Cell 91: 325-334, 1997.

88. Khanna KK, Keating KE, Kozlov S, et al: ATM associates with and phosphorylates p53: mapping the region of interaction. Nat Genet 20: 398-400, 1998.

89. Woods DB and Vousden KH: Regulation of p53 function. Exp Cell Res 264: 56-66, 2001

90. Bruins W, Zwart E, Attardi LD, et al: Increased sensitivity to UV radiation in mice with a $\mathrm{p} 53$ point mutation at Ser389. Mol Cell Biol 24: 8884-8894, 2004.

91. Lu H, Taya Y, Ikeda M and Levine AJ: Ultraviolet radiation, but not gamma radiation or etoposide-induced DNA damage, results in the phosphorylation of the murine p53 protein at serine-389. Proc Natl Acad Sci USA 95: 6399-6402, 1998.

92. Saito Si, Yamaguchi H, Higashimoto Y, et al: Phosphorylation site interdependence of human p53 post-translational modifications in response to stress. J Biol Chem 278: 37536-37544, 2003. 
93. Gu W and Roeder RG: Activation of p53 sequence-specific DNA binding by acetylation of the p53 C-terminal domain. Cell 90: 595-606, 1997.

94.Liu L, Scolnick DM, Trievel RC, et al: p53 sites acetylated in vitro by PCAF and p300 are acetylated in vivo in response to DNA damage. Mol Cell Biol 19: 1202-1209, 1999.

95. Tang Y, Luo J, Zhang W and Gu W: Tip60-dependent acetylation of p53 modulates the decision between cell-cycle arrest and apoptosis. Mol Cell 24: 827-839, 2006.

96. Feng L, Lin T, Uranishi $\mathrm{H}, \mathrm{Gu}$ W and $\mathrm{Xu} \mathrm{Y}$ : Functional analysis of the roles of posttranslational modifications at the p53 C terminus in regulating p53 stability and activity. Mol Cell Biol 25: 5389-5395, 2005 .

97. Tang Y, Zhao W, Chen Y, Zhao Y and Gu W: Acetylation is indispensable for p53 activation. Cell 133: 612-626, 2008.

98. Luo J, Su F, Chen D, Shiloh A and Gu W: Deacetylation of p53 modulates its effect on cell growth and apoptosis. Nature 408: 377-381, 2000.

99. Vaziri H, Dessain SK, Ng Eaton E, et al: hSIR2(SIRT1) functions as an NAD-dependent p53 deacetylase. Cell 107: 149-159, 2001.

100. Luo J, Nikolaev AY, Imai S, et al: Negative control of p53 by Sir2alpha promotes cell survival under stress. Cell 107: 137-148, 2001

101. Chuikov S, Kurash JK, Wilson JR, et al: Regulation of p53 activity through lysine methylation. Nature 432: 353-360, 2004.

102. Huang J, Perez-Burgos L, Placek BJ, et al: Repression of p53 activity by Smyd2-mediated methylation. Nature 444: 629-632, 2006.

103. Shi X, Kachirskaia I, Yamaguchi H, et al: Modulation of p53 function by SET8-mediated methylation at lysine 382. Mol Cell 27: 636-646, 2007

104.Jansson M, Durant ST, Cho EC, et al: Arginine methylation regulates the p53 response. Nat Cell Biol 10: 1431-1439, 2008.

105. Huang J, Sengupta R, Espejo AB, et al: p53 is regulated by the lysine demethylase LSD1. Nature 449: 105-108, 2007.

106. Ito A, Kawaguchi Y, Lai CH, et al: MDM2-HDAC1-mediated deacetylation of p53 is required for its degradation. EMBO J 21: 6236-6245, 2002

107. Li M, Luo J, Brooks CL and Gu W: Acetylation of p53 inhibits its ubiquitination by Mdm2. J Biol Chem 277: 50607-50611, 2002.

108. Ivanov GS, Ivanova T, Kurash J, et al: Methylation-acetylation interplay activates p53 in response to DNA damage. Mol Cell Biol 27: 6756-6769, 2007.

109. D'Orazi G, Cecchinelli B, Bruno T, et al: Homeodomaininteracting protein kinase-2 phosphorylates p53 at Ser 46 and mediates apoptosis. Nat Cell Biol 4: 11-19, 2002.

110. Hofmann TG, Möller A, Sirma H, et al: Regulation of p53 activity by its interaction with homeodomain-interacting protein kinase-2. Nat Cell Biol 4: 1-10, 2002.

111. Espinosa $\mathrm{J}$ : Mechanisms of regulatory diversity within the p53 transcriptional network. Oncogene 27: 4013-4023, 2008.

112. Taira N, Nihira K, Yamaguchi T, Miki Y and Yoshida K: DYRK2 is targeted to the nucleus and controls p53 via Ser46 phosphorylation in the apoptotic response to DNA damage. Mol Cell 25: 725-738, 2007.

113. Oda K, Arakawa H, Tanaka T, et al: p53AIP1, a potential mediator of p53-dependent apoptosis, and its regulation by Ser-46-phosphorylated p53. Cell 102: 849-862, 2000.

114. Mayo LD, Seo YR, Jackson MW, et al: Phosphorylation of human p53 at serine 46 determines promoter selection and whether apoptosis is attenuated or amplified. J Biol Chem 280: 25953-25959, 2005.

115. Bulavin DV, Saito S, Hollander MC, et al: Phosphorylation of human p53 by p38 kinase coordinates N-terminal phosphorylation and apoptosis in response to UV radiation. EMBO J 18 : 6845-6854, 1999

116. Shmueli A and Oren M: Mdm2: p53's lifesaver? Mol Cell 25: 794-796, 2007.

117. Rinaldo C, Prodosmo A, Mancini F, et al: MDM2-regulated degradation of HIPK2 prevents p53Ser46 phosphorylation and DNA damage-induced apoptosis. Mol Cell 25: 739-750, 2007.

118. Puca R, Nardinocchi L, Sacchi A, Rechavi G, Givol D and D'Orazi G: HIPK2 modulates p53 activity towards pro-apoptotic transcription. Mol Cancer 8: 85, 2009.

119. Yoshida K, Liu H and Miki Y: Protein kinase C delta regulates Ser46 phosphorylation of p53 tumor suppressor in the apoptotic response to DNA damage. J Biol Chem 281: 5734-5740, 2006.
120. Okoshi R, Ozaki T, Yamamoto H, et al: Activation of AMPactivated protein kinase induces p53-dependent apoptotic cell death in response to energetic stress. J Biol Chem 283: 3979-3987, 2008.

121.Perfettini JL, Castedo M, Nardacci R, et al: Essential role of p53 phosphorylation by p38 MAPK in apoptosis induction by the HIV-1 envelope. J Exp Med 201: 279-289, 2005.

122. Sykes SM, Mellert HS, Holbert MA, et al: Acetylation of the p53 DNA-binding domain regulates apoptosis induction. Mol Cell 24: 841-851, 2006.

123. Sakaguchi K, Herrera JE, Saito S, et al: DNA damage activates p53 through a phosphorylation-acetylation cascade. Genes Dev 12: 2831-2841, 1998 .

124. Knights C: Distinct p53 acetylation cassettes differentially influence gene-expression patterns and cell fate. J Cell Biol 173: 533-544, 2006.

125.Le Cam L, Linares LK, Paul C, et al: E4F1 is an atypical ubiquitin ligase that modulates p53 effector functions independently of degradation. Cell 127: 775-788, 2006.

126. Chao C, Wu Z, Mazur SJ, et al: Acetylation of mouse p53 at lysine 317 negatively regulates p53 apoptotic activities after DNA damage. Mol Cell Biol 26: 6859-6869, 2006.

127. Ou Y-H, Chung P-H, Sun T-P and Shieh S-Y: p53 C-terminal phosphorylation by $\mathrm{CHK} 1$ and $\mathrm{CHK} 2$ participates in the regulation of DNA-damage-induced C-terminal acetylation. Mol Biol Cell 16: 1684-1695, 2005.

128. Yamaguchi H, Woods NT, Piluso LG, et al: p53 acetylation is crucial for its transcription-independent proapoptotic functions. J Biol Chem 284: 11171-11183, 2009.

129. Scoumanne A, Zhang J and Chen X: PRMT5 is required for cell-cycle progression and p53 tumor suppressor function. Nucleic Acids Res 37: 4965-4976, 2009.

130. Laptenko $\mathrm{O}$ and Prives C: Transcriptional regulation by $\mathrm{p} 53$ : one protein, many possibilities. Cell Death Differ 13: 951-961, 2006.

131.Avantaggiati ML, Ogryzko V, Gardner K, Giordano A, Levine AS and Kelly K: Recruitment of p300/CBP in p53dependent signal pathways. Cell 89: 1175-1184, 1997.

132. Shikama N, Lee CW, France S, et al: A novel cofactor for p300 that regulates the p53 response. Mol Cell 4: 365-376, 1999.

133. Demonacos C, Krstic-Demonacos M and La Thangue NB: A TPR motif cofactor contributes to p300 activity in the p53 response. Mol Cell 8: 71-84, 2001.

134. Kitagawa M, Lee SH and McCormick F: Skp2 suppresses p53dependent apoptosis by inhibiting p300. Mol Cell 29: 217-231, 2008.

135. Lee D, Kim JW, Seo T, Hwang SG, Choi E-J and Choe J: SWI/SNF complex interacts with tumor suppressor p53 and is necessary for the activation of p53-mediated transcription. J Biol Chem 277: 22330-22337, 2002.

136. Xu Y, Zhang J and Chen X: The activity of p53 is differentially regulated by Brm- and Brg1-containing SWI/SNF chromatin remodeling complexes. J Biol Chem 282: 37429-37435, 2007.

137. Gamper AM and Roeder RG: Multivalent binding of p53 to the STAGA complex mediates coactivator recruitment after UV damage. Mol Cell Biol 28: 2517-2527, 2008.

138. Ard PG, Chatterjee C, Kunjibettu S, Adside LR, Gralinski LE and McMahon SB: Transcriptional regulation of the mdm2 oncogene by p53 requires TRRAP acetyltransferase complexes. Mol Cell Biol 22: 5650-5661, 2002.

139. Bergamaschi D, Samuels Y, O'Neil NJ, et al: iASPP oncoprotein is a key inhibitor of p53 conserved from worm to human. Nat Genet 33: 162-167, 2003.

140.Samuels-Lev Y, O'Connor DJ, Bergamaschi D, et al: ASPP proteins specifically stimulate the apoptotic function of p53. Mol Cell 8: 781-794, 2001.

141.Bergamaschi D, Samuels Y, Sullivan A, et al: iASPP preferentially binds $\mathrm{p} 53$ proline-rich region and modulates apoptotic function of codon 72-polymorphic p53. Nat Genet 38: 1133-1141, 2006.

142. Das S, Raj L, Zhao B, et al: Hzf Determines cell survival upon genotoxic stress by modulating p53 transactivation. Cell 130: 624-637, 2007

143. Budhram-Mahadeo VS, Bowen S, Lee S, et al: Brn-3b enhances the pro-apoptotic effects of p53 but not its induction of cell cycle arrest by cooperating in trans-activation of bax expression. Nucleic Acids Res 34: 6640-6652, 2006.

144.Tian C, Xing G, Xie P, et al: KRAB-type zinc-finger protein Apak specifically regulates p53-dependent apoptosis. Nat Cell Biol 11: 580-591, 2009. 
145. Homer C, Knight DA, Hananeia L, et al: Y-box factor YB1 controls p53 apoptotic function. Oncogene 24: 8314-8325, 2005.

146. Tanaka T, Ohkubo S, Tatsuno I and Prives C: hCAS/CSE1L associates with chromatin and regulates expression of select p53 target genes. Cell 130: 638-650, 2007.

147. Mirnezami AH, Campbell SJ, Darley M, Primrose JN, Johnson PWM and Blaydes JP: Hdm2 recruits a hypoxiasensitive corepressor to negatively regulate p53-dependent transcription. Curr Biol 13: 1234-1239, 2003.

148. Subramanian T and Chinnadurai G: Pro-apoptotic activity of transiently expressed BCL-2 occurs independent of BAX and BAK. J Cell Biochem 89: 1102-1114, 2003.

149. Schumm K, Rocha S, Caamano J and Perkins ND: Regulation of p53 tumour suppressor target gene expression by the p52 NF-kappaB subunit. EMBO J 25: 4820-4832, 2006.

150. Wu WS, Heinrichs S, Xu D, et al: Slug antagonizes p53mediated apoptosis of hematopoietic progenitors by repressing puma. Cell 123: 641-653, 2005.

151. Koeppel M, van Heeringen SJ, Smeenk L, Navis AC, JanssenMegens EM and Lohrum M: The novel p53 target gene IRF2BP2 participates in cell survival during the p53 stress response. Nucleic Acids Res 37: 322-335, 2009.

152. Tanikawa C, Furukawa Y, Yoshida N, Arakawa H, Nakamura Y and Matsuda K: XEDAR as a putative colorectal tumor suppressor that mediates p53-regulated anoikis pathway. Oncogene 28: 3081-3092, 2009.

153. Mantovani F, Tocco F, Girardini J, et al: The prolyl isomerase Pin 1 orchestrates p53 acetylation and dissociation from the apoptosis inhibitor iASPP. Nat Struct Mol Biol 14: 912-920, 2007.

154. Flores ER, Sengupta S, Miller JB, et al: Tumor predisposition in mice mutant for p63 and p73: Evidence for broader tumor suppressor functions for the p53 family. Cancer Cell 7: 363-373, 2005 .

155. Flores ER, Tsai KY, Crowley D, et al: p63 and p73 are required for p53-dependent apoptosis in response to DNA damage. Nature 416: 560-564, 2002.

156. Tomasini R, Tsuchihara K, Wilhelm M, et al: TAp73 knockout shows genomic instability with infertility and tumor suppressor functions. Genes Dev 22: 2677-2691, 2008

157. Senoo M, Manis JP, Alt FW and McKeon F: p63 and p73 are not required for the development and p53-dependent apoptosis of T cells. Cancer Cell 6: 85-89, 2004

158. Smeenk L, Van Heeringen S, Koeppel M, et al: Characterization of genome-wide p53-binding sites upon stress response. Nucleic Acids Res 36: 3639-3654, 2008.

159. Melino G, Lu X, Gasco M, Crook T and Knight RA: Functional regulation of p73 and p63: development and cancer. Trends Biochem Sci 28: 663-670, 2003.

160. Bourdon J, Fernandes K, Murray-Zmijewski F, et al: p53 isoforms can regulate p53 transcriptional activity. Genes Dev 19: 2122-2137, 2005

161. He L, He X, Lim LP, et al: A microRNA component of the p53 tumour suppressor network. Nature 447: 1130-1134, 2007.

162. Hermeking H: p53 enters the microRNA world. Cancer Cell 12: 414-418, 2007.

163. Yamakuchi $M$ and Lowenstein CJ: MiR-34, SIRT1 and p53: The feedback loop. Cell Cycle 8: 712-715, 2009.

164. Braun CJ, Zhang X, Savelyeva I, et al: p53-Responsive micrornas 192 and 215 are capable of inducing cell cycle arrest. Cancer Res 68: 10094-10104, 2008.

165. Georges SA, Chau BN, Braun CJ, Zhang X and Dobbelstein M: Cell cycle arrest or apoptosis by p53: are microRNAs-192/215 and -34 making the decision? Cell Cycle 8: 680-681, 2009.
166. Song B, Wang Y, Kudo K, Gavin EJ, Xi Y and Ju J: miR-192 Regulates dihydrofolate reductase and cellular proliferation through the p53-microRNA circuit. Clin Cancer Res 14: 8080-8086, 2008.

167. Suzuki HI, Yamagata K, Sugimoto K, Iwamoto T, Kato S and Miyazono K: Modulation of microRNA processing by $\mathrm{p} 53$. Nature 460: 529-533, 2009.

168. Walhout A: Unraveling transcription regulatory networks by protein-DNA and protein-protein interaction mapping. Genome Res 16: 1445-1454, 2006.

169. Lander ES, Linton LM, Birren B, et al: Initial sequencing and analysis of the human genome. Nature 409: 860-921, 2001.

170. Venter JC, Adams MD, Myers EW, et al: The sequence of the human genome. Science 291: 1304-1351, 2001.

171.Ren B, Robert F, Wyrick JJ, et al: Genome-wide location and function of DNA binding proteins. Science 290: 2306-2309, 2000.

172. Barski A and Zhao K: Genomic location analysis by ChIP-Seq. J Cell Biochem 107: 11-18, 2009.

173. Cawley S, Bekiranov S, Ng HH, et al: Unbiased mapping of transcription factor binding sites along human chromosomes 21 and 22 points to widespread regulation of noncoding RNAs. Cell 116: 499-509, 2004.

174. Kaneshiro K, Tsutsumi S, Tsuji S, Shirahige K and Aburatani H: An integrated map of p53-binding sites and histone modification in the human ENCODE regions. Genomics 89: 178-188, 2007.

175. Krieg A: Functional analysis of p53 binding under differential stresses. Mol Cell Biol 26: 7030-7045, 2006.

176. Wei CL, Wu Q, Vega VB, et al: A global map of p53 transcription-factor binding sites in the human genome. Cell 124: 207-219, 2006.

177. Yang A, Zhu Z, Kapranov P, et al: Relationships between p63 binding, DNA sequence, transcription activity, and biological function in human cells. Mol Cell 24: 593-602, 2006.

178. Hearnes JM, Mays DJ, Schavolt KL, Tang L, Jiang X and Pietenpol JA: Chromatin immunoprecipitation-based screen to identify functional genomic binding sites for sequence-specific transactivators. Mol Cell Biol 25: 10148-10158, 2005.

179. Shaked H, Shiff I, Kott-Gutkowski M, Siegfried Z, Haupt Y and Simon I: Chromatin immunoprecipitation-on-chip reveals stress-dependent p53 occupancy in primary normal cells but not in established cell lines. Cancer Res 68: 9671-9677, 2008.

180.Ceribelli M, Alcalay M, Vigano MA and Mantovani R: Repression of new p53 targets revealed by ChIP on chip experiments. Cell Cycle 5: 1102-1110, 2006.

181. Vrba L, Junk D, Novak P and Futscher B: p53 induces distinct epigenetic states at its direct target promoters. BMC Genomics 9: 486, 2008.

182. Hupp TR, Meek DW, Midgley CA and Lane D: Regulation of the specific DNA binding function of p53. Cell 71: 875-886, 1992.

183. Hoh J, Jin S, Parrado T, Edington J, Levine AJ and Ott J: The p53 $\mathrm{MH}$ algorithm and its application in detecting p53responsive genes. Proc Natl Acad Sci USA 99: 8467-8472, 2002.

184. Viganò $\mathrm{M}$, Lamartine $\mathrm{J}$, Testoni $\mathrm{B}$, et al: New p63 targets in keratinocytes identified by a genome-wide approach. EMBO J 25: 5105-5116, 2006.

185.El-Deiry WS: Regulation of p53 downstream genes. Semin Cancer Biol 8: 345-357, 1998.

186. Sbisa E, Catalano D, Grillo G, et al: p53FamTaG: a database resource of human p53, p63 and p73 direct target genes combining in silico prediction and microarray data. BMC Bioinformatics 8 (Suppl 1): S20, 2007. 